\title{
Surgical aspects of thoracoscopy and efficacy of right thoracoscopy in minimally invasive repair of pectus excavatum
}

\author{
Amulya K. Saxena, MD, Christoph Castellani, MD, and Michael E. Höllwarth, MD
}

From the Department of Pediatric Surgery, Medical University of Graz, Austria.

Received for publication Sept 12, 2006; revisions received Jan 19, 2007; accepted for publication Jan 23, 2007.

Address for reprints: Amulya K. Saxena, MD, Department of Pediatric Surgery, Medical University of Graz, Auenbruggerplatz 34, A-8034 Graz, Austria (E-mail: amulya.saxena@meduni-graz.at).

J Thorac Cardiovasc Surg 2007;133:1201-5 $0022-5223 / \$ 32.00$

Copyright $(9) 2007$ by The American Association for Thoracic Surgery

doi:10.1016/j.jtcvs.2007.01.040
Objective: Minimally invasive repair of pectus excavatum has been established as the preferred technique for the repair of funnel chest deformity. Original techniques of pectus bar placement have been modified to improve the safety of the procedures. The aim of this study is to evaluate the efficacy of right thoracoscopy and to identify factors responsible for complications related to thoracoscopy in minimally invasive repair of pectus excavatum, along with a review of the literature.

Methods: A retrospective analysis was performed on patients who have had a thoracoscopically assisted minimally invasive repair of pectus excavatum at the Department of Pediatric Surgery, Medical University of Graz, Austria, between 2000 and 2006. The port was inserted through the right lateral chest wall in all patients to obtain visual access for bar insertion.

Results: Charts of 160 patients (130 male and 30 female) with an age range from 5 to 38 years were evaluated. Surgical time ranged from 25 to 255 minutes (mean 66 minutes). Complications primarily related to thoracoscopy were found in 16 patients $(10 \%)$.There was 1 case of the port trocar piercing through the liver. Incomplete gas evacuation caused postoperative pneumothorax in 15 patients, 5 requiring thoracocentesis and 2 chest tubes.

Conclusions: Insertion of the port in the right lateral chest wall is safe and provides optimum visual access during the minimally invasive repair procedure. Careful interpretation of chest films can assist in judicious determination of the port site. Optimum pressures and near complete evacuation of the insufflation gases can drastically reduce complications. Alternative access sites such as port insertion above the level of bar placement or left-sided and/or bilateral thoracoscopy may not be necessary.

$\mathrm{M}$ ost surgeons worldwide have adopted the minimally invasive technique for the repair of pectus excavatum (MIRPE) as the procedure of choice in the treatment of young children, teenagers, and adults with this anterior chest wall deformity. ${ }^{1,2}$ Since its introduction, this technique has quickly gained significant popularity among patients and surgeons, mainly because it is perceived as a minor invasive operation with good esthetic results. Bilateral short thoracic incisions are made, and a custom-modeled steel strut is guided below the sternum. The initial procedure described by Donald Nuss and associates ${ }^{1}$ in 1998 did not use thoracoscopic controls; however, in 2002 an updated experience and a modification of the MIRPE technique was reported by the same group using routine thoracoscopy via the right side of the chest to improve safety during mediastinal dissecton. ${ }^{3}$ Although thoracoscopy gained acceptance after its introduction during this time and is now an integral part of the MIRPE procedure at most centers, it has been associated with complications in MIRPE. However, reports dealing with the complications related to thoracoscopy in 

Abbreviations and Acronyms
$\mathrm{CO}_{2}=$ carbon dioxide
MIRPE $=$ minimally invasive repair of pectus excavatum
VATS $=$ video-assisted thoracoscopic surgery

MIRPE are scarce and have been completely overshadowed by complications observed with the pectus bar, including the report on adult patients from our center. ${ }^{4,5}$ The aim of our study was to evaluate the efficacy of right thoracoscopy in MIRPE with the intention of identifying complications and their prevalence along with the precautions and preventions to be taken to avoid them.

\section{Patients and Methods}

The hospital charts of 160 patients who underwent pectus excavatum repair between April 2000 and April 2006 were retrospectively reviewed after informed consent of the patients. There were 130 male and 30 female patients with the mean age at the time of operation being 16.4 years (range 5-38 years). In this group, 3 patients were included who had recurrent funnel chest after unsuccessful repair via different procedures.

The MIRPE procedure was performed by making small bilateral transverse incisions on either side of the chest. A Walter Lorenz strut (Walter Lorenz Surgical, Jacksonville, Fla) of appropriate size was selected and custom modeled to the desired chest contour. Right-sided thoracoscopy was performed by insertion of a 5-mm port through the right lateral chest wall just above the estimated level of the diaphragm in the anterior axillary line. The intrathoracic placement of the port was confirmed by observing lung tissue with a $5-\mathrm{mm}$ scope after which a pressure of 4 to 5 $\mathrm{mm} \mathrm{Hg}$ was used for insufflation. This was considered sufficient for the pneumothorax. The introducer was inserted into the thorax from the right side and was used to guide the strut into the desired position. After the strut was flipped, a stabilizer was used on the right side and steel wires or polydioxanone sutures (PDS; Ethicon, Inc, Somerville, NJ) were placed around the strut and the underlying ribs, anchoring them together. At the end of the procedure, after closure of the thoracic incisions and before removal of the port, the anesthetist applied positive-pressure ventilation to evacuate the accumulated carbon dioxide $\left(\mathrm{CO}_{2}\right)$. At this time, the patient was brought into a left semilateral head drop position so as to raise the level of the port to the highest position and facilitate maximum gas evacuation from the thorax. Routine postoperative chest films were part of our protocol and were taken to evaluate the position of the bar as well as to evaluate the thoracic cavity with regard to pneumothorax.

\section{Results}

One hundred sixty patients have undergone the MIRPE procedure. The pectus bar was introduced in all cases from the right side of the chest under thoracoscopic visualization. Thirteen patients required a second bar owing to the severity of the deformity. Surgical time ranged from 25 to
255 minutes (mean operative time, 66 minutes). Right-sided thoracoscopy was performed in all 160 patients during the MIRPE.

Altogether, 16 (10\%) complications directly related to thoracoscopy were observed during MIRPE. The only major complication was the piercing of the port trocar through the liver in 1 patient $(0.6 \%)$. A concomitant diagnostic laparoscopy in the same patient showed minimal blood loss in the abdomen, and the liver perforation did not require further intervention. Fifteen (9.4\%) patients had a pneumothorax detected on chest films after the procedure. However, only 7 (4.4\%) patients required further intervention, with thoracocentesis performed in $5(3.1 \%)$ and chest tube placement in $2(1.3 \%)$ patients, respectively.

In 3 patients operated on for recurrent funnel chest, thoracoscopy was useful in the exposure of adhesions. It was further beneficial in the dissections of the thoracic adhesions before the introduction of the bar.

\section{Discussion}

Most publications dealing with MIRPE have focused on minimizing the bar and stabilizer dislocation, probably because this is still the most important issue at many centers and was evident from the initial report of Donald Nuss $(8.8 \%) .{ }^{6,7}$ The same report pointed out a $52 \%$ complication rate resulting from residual pneumothorax, with intervention required in $2.7 \%$ of the cases. Despite this initial report, little attention has been paid in the literature to the aspects of thoracoscopy and its complications, which rank second to those of bar displacement in MIRPE.

The most important aspect in thoracoscopy is the determination of the suitable point of insertion of the port. Port placement site in MIRPE differs substantially from those generally chosen for other video-assisted thoracoscopic surgery (VATS) procedures. Optimum visualization in MIRPE requires the port insertion almost at the level of the diaphragmatic recess, which is markedly lower than the midthoracic placement of ports for VATS. Right-sided port insertion in MIRPE carries a risk of injury to the diaphragm or the liver. In the case of liver perforation in our series, there was an error in interpretation of the elevated diaphragm on the right side in the chest films. Chest films and computed tomography of patients with pectus deformity have mainly evaluated the severity of the deformity and the relation of the depression to the heart. ${ }^{89}$ However, if thoracoscopically assisted MIRPE is to be performed, equal emphasis must be placed on the evaluation of the diaphragm and the upper abdominal parenchymatous organs to avoid injury during port insertion. Assessment of the diaphragm should be included as part of the preoperative chest radiograph protocol.

Once the port has been placed in the hemithorax, examination with a scope is the first procedure before insufflation 
is started. $\mathrm{CO}_{2}$ insufflation with positive pressure has been advocated to aid in the creation of an artificial pneumothorax when single lung ventilation is not used..$^{10}$ Insufflation $\mathrm{CO}_{2}$ pressures in MIRPE have been reported in a wide range and vary from $4 \mathrm{~mm} \mathrm{Hg}$ (standard at our center) up to as high as $10 \mathrm{~mm} \mathrm{Hg}$ reported by others. ${ }^{11,12}$ Although $\mathrm{CO}_{2}$ insufflation has been carried out safely under various pressures, it has been observed that insufflation pressures as low as $5 \mathrm{~mm} \mathrm{Hg}$ may result in significant decrease in cardiac index, mean arterial pressure, stroke volume, and left ventricular stroke work index. ${ }^{13}$ Therefore, care should also be taken to use the minimum pressure needed, especially after the substernal tunnel has been created, because the ipsilateral insufflation can be transferred to the contralateral chest and lead to difficulty in ventilation. We recommend insufflation pressures in the range of 4 to $5 \mathrm{~mm} \mathrm{Hg}$ for thoracoscopy in MIRPE.

The type of scope used has not been reported uniformly, and its importance has been underestimated by many centers reporting on thoracoscopically assisted MIRPE. ${ }^{14,15}$ Scopes with an angle of vision of $30^{\circ}$ are most widely used at centers worldwide in the field of laparoscopy and thoracoscopy and have also been used for MIRPE because of their ready availability. Zallen and Glick ${ }^{12}$ have even reported the use of separate $45^{\circ}$ and $70^{\circ}$ scopes for mediastinal dissection and placement of wires to secure the bar, respectively. After our experience with wire breakage complications, pectus bars have been secured to the ribs with stabilizer plates using PDS cords. Suturing of PDS cords does not require special scopes, and no complication with the use of PDS cords securing the bar and stabilizer on the underlying rib have been observed in our series. Scopes with an angle of vision of $30^{\circ}$ have provided an optimum operative field of vision, and we recommend their use in MIRPE. Investing in scopes of different sizes such as $45^{\circ}$ and $70^{\circ}$ does not offer any added advantages to the procedure if port site is properly selected.

Thoracoscopy was effectively applied only on the right side of the chest in our series for the placement of the pectus bar. Some authors have suggested the use of left thoracoscopy for MIRPE, with advantages in terms of eliminating the risk of cardiothoracic injury. ${ }^{16}$ However, it is easier to perform the mediastinal dissection of the substernal tissue from the pericardial tissue from the right side when compared with the limited view achieved with a left-sided approach (Figure 1). Bilateral thoracoscopy has been suggested by other authors, but significant advantages of its use have not been elaborated. ${ }^{15}$ Determination of pulmonary tissue entrapping between the bar and the chest at the time of flipping could be a reason for the use of bilateral thoracoscopy; however, pulmonary tissue entrapping is theoretically not possible with positive insufflation pressures. Furthermore, bilateral thoracoscopy could double the chances

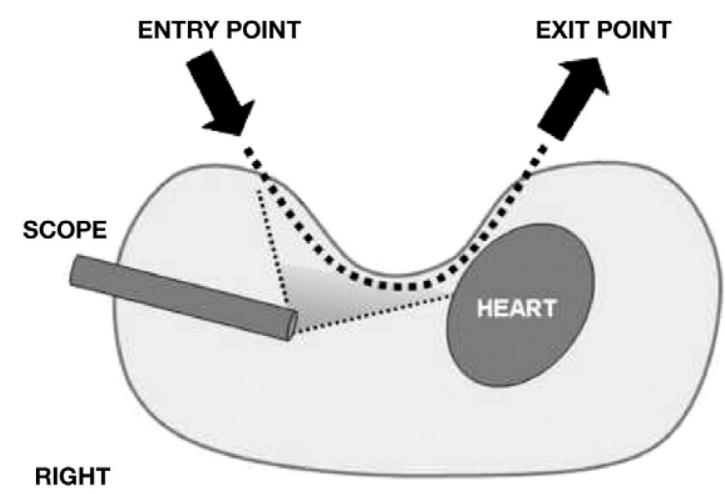

LEFT

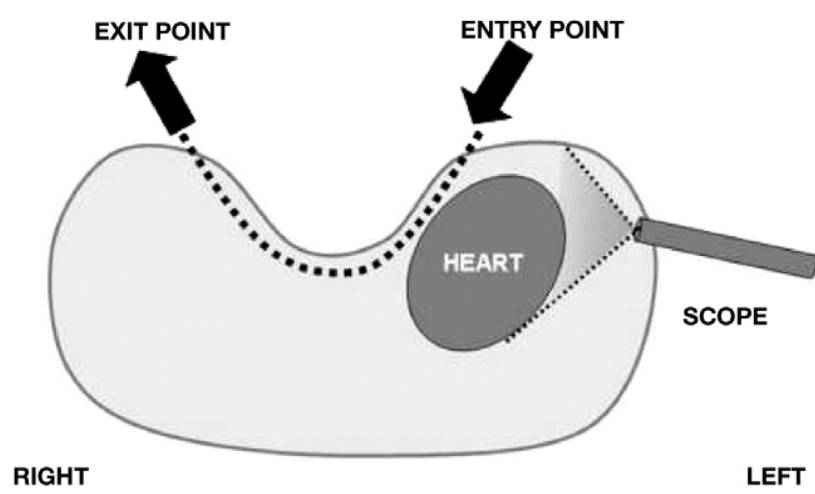

Figure 1. Schematic view demonstrating the field of view obtained during MIRPE. Right-sided thoracoscopy (top) allows optimum view of the deformity when compared with the left side (bottom) with regard to insertion of the introducer. The heart blocks the visual field of the depression when approached from the left side. MIRPE, Minimally invasive repair of pectus excavatum.

of chest wall paresthesia resulting from port injury of the intercostal nerves, which is a complication of thoracoscopy in VATS, but has not been reported in the MIRPE studies so far. ${ }^{17}$ Since, the efficacy and safety of single-port technique for VATS has been advocated, ${ }^{18}$ we consider only rightsided thoracoscopy to be sufficient for mediastinal exposure and dissection in MIRPE.

Pneumothorax is the most common complication of thoracoscopy in MIRPE (Table 1). Reports of pneumothorax-associated problems decreased remarkably after it was understood and considered mandatory to remove all insufflated gas from the thorax after completion of the procedure. The trapped $\mathrm{CO}_{2}$ can be removed when the anesthetist applies positive-pressure ventilation and a positive end-expiratory pressure at the end of the procedure. ${ }^{19}$ Keeping the patient in the left semilateral head drop position and evacuating the gas under positive end-expiratory pressure are simple steps at the end of the MIRPE procedure, before final closure, that have drastically reduced the incidence of pneumothorax in our series. However, repair of recurrent failed funnel chest repair in a large series published recently has again demonstrated this 
TABLE 1. Incidence of pneumothorax resulting from thoracoscopy in MIRPE reported in the literature

\begin{tabular}{|c|c|c|c|c|c|c|}
\hline \multirow[b]{2}{*}{ First author } & \multirow[b]{2}{*}{ Year of publication } & \multirow[b]{2}{*}{ No. of patients } & \multicolumn{2}{|c|}{ Pneumothorax } & \multicolumn{2}{|c|}{$\begin{array}{c}\text { Pneumothorax } \\
\text { necessitating intervention }\end{array}$} \\
\hline & & & Patients & Percent & Patients & Percent \\
\hline Nuss $^{6}$ & 2002 & 329 & 74 & 52 & 9 & 2.7 \\
\hline Croitoru $^{3}$ & 2002 & 303 & 155 & 59.7 & 8 & 2.6 \\
\hline Uemera $^{15}$ & 2003 & 107 & 1 & 0.9 & 1 & 0.9 \\
\hline Boehm 11 & 2004 & 21 & 2 & 9.5 & 2 & 9.5 \\
\hline Futagawa $^{19}$ & 2005 & 21 & 7 & 33.3 & - & - \\
\hline $\mathrm{Ong}^{7}$ & 2005 & 78 & 40 & 55.5 & 1 & 1.3 \\
\hline Hendrickson ${ }^{16}$ & 2005 & 51 & 20 & 39.2 & 2 & 4 \\
\hline Croitoru $^{20}$ & 2005 & 50 & 35 & 70 & 12 & 24 \\
\hline Our series & 2007 & 160 & 15 & 9.4 & 7 & 4.4 \\
\hline
\end{tabular}

MIRPE, Minimally invasive repair of pectus excavation.

problem in $70 \%$ of patients, with $24 \%$ requiring interventions. ${ }^{20}$ An alternative to address this problem would be to place a $16 \mathrm{~F}$ or $20 \mathrm{~F}$ chest catheter during surgery that can be pulled out in the recovery room.

Patient positioning before the implementation of thoracoscopy in MIRPE did not play a major role in influencing the complications. With thoracoscopy, it is necessary to have the surgeon and the cameraman on the same side of the patient. Under anesthesia, the patient has decreased normal resting tones that allow the patient to assume nonphysiologic positions. This leads to nerve ischemia when the vessels supplying the nerves become compressed. ${ }^{21}$ If the angle of upper extremity abduction exceeds $90^{\circ}$, stretching and compression of the brachial plexus can occur. ${ }^{22}$ Therefore, we recommend placing the patient on the right edge of the table with both the arms extended $90^{\circ}$ at the shoulder joint. MIRPE with the right-sided thoracoscopy approach allows the cameraman to be positioned close to the right thigh area and provides sufficient space for the surgeon on the right side of the patient's chest to operate, without the need to overextend the upper extremity. Positioning of the operating team and the patient as described helps to minimize the possibility of insult to the brachial plexus.

Thoracoscopy in our hands is an incorporated part of the MIRPE procedure. Although it is simple to perform and has rendered the MIRPE safer, it can be associated with pitfalls. The possible complications arising from thoracoscopy in MIRPE have been elaborated, with ways to avoid them. Right-sided thoracoscopy is an effective aid to MIRPE and its benefits have been highlighted by this study.

\section{References}

1. Nuss D, Kelly RE, Croitoru DP, Katz ME. A 10-year review of a minimally invasive technique for the correction of pectus excavatum. J Pediatr Surg. 1998;33:545-52.
2. Hebra A. Minimally invasive pectus surgery. Chest Surg Clin North Am. 2000;10:329-39.

3. Croitoru DP, Kelly RE, Goretsky MJ, Lawson ML, Swoveland B. Experience and modification update for the minimally invasive Nuss technique for pectus excavatum repair in 303 patients. J Pediatr Surg. 2002;37:437-45.

4. Hebra A, Swoveland B, Egbert M, Tagge EP, Georgeson K, Otherson $\mathrm{HB}$, et al. Outcome analysis of minimally invasive repair of pectus excavatum: review of 251 cases. J Pediatr Surg. 2000;35:252-8.

5. Schalamon J, Pokall S, Windhaber J, Hoellwarth ME. Minimally invasive correction of pectus excavatum in adult patients. $J$ Thorac Cardiovasc Surg. 2006;132:524-9.

6. Nuss D, Croitrou DP, Kelly RE, Goretsky MJ, Nuss KJ, Gustin TS. Review and discussion of the complications of minimally invasive pectues repair. Eur J Pediatr Surg. 2002;12:230-4.

7. Ong CC, Choo K, Morreau P, Auldist A. The learning curve in learning the curve: a review of Nuss procedures in teenagers. ANZ J Surg. 2005;75:421-4.

8. Ohno K, Nakahira M, Takeuchi S, Shiokawa C, Moriuchi T, Harumoto $\mathrm{K}$, et al. Indications for surgical treatment of funnel chest by chest radiograph. Pediatr Surg Int. 2001;17:591-5.

9. Chuang JH, Wan YL. Evaluation of pectus excavatum with repeated CT scan. Pediatr Radiol. 1995; 5:654-6.

10. Landreneau RJ, Mack MJ, Hazelrigg SR, Dowling RD, Acuff TE, Magee MJ, et al. Video-assisted thoracic surgery: basic technical concepts and intercostal approach strategies. Ann Thorac Surg. 1992; 54:800-7.

11. Boehm RA, Muensterer OJ, Till H. Comparing minimally invasive funnel chest repair versus the conventional technique: an outcome analysis in children. Plast Reconstr Surg. 2004;114:668-73.

12. Zallen GS, Glick PL. Miniature access pectus excavatum repair: lessons we have learned. J Pediatr Surg. 2004;39:685-9.

13. Jones DR, Graeber GM, Tanguilig GG, Hobbs G, Murray GF. Effects of insufflation on hemodynamics during thoracoscopy. Ann Thorac Surg. 1993;55:1379-82.

14. Park HJ, Le SY, Le CS. Complications associated with the Nuss procedure: analysis of risk factors and suggested measures for prevention of complications. J Pediatr Surg. 2004;39:391-5.

15. Uemura S, Nakagawa Y, Yoshida A, Choda Y. Experience in 100 cases with the Nuss procedure using a technique for stabilization of the pectus bar. Pediatr Surg Int. 2003;19:186-9.

16. Hendrickson RJ, Bensard DD, Janik JS, Patrick DA. Efficacy of left thoracoscopy and blunt mediastinal dissection during the Nuss procedure for pectus excavatum. J Pediatr Surg. 2005;40:1312-4.

17. Sihoe ADL, Au SSW, Cheung ML, Chow IKL, Chu KM, Law CY, et al. Incidence of chest wall paresthesia after video-assisted thoracic 
surgery for primary spontaneous pneumothorax. Eur J Cardiothorac Surg. 2004;25:1054-8.

18. Migliore M. Efficacy and safety of single-trocar technique for minimally invasive surgery of the chest in the treatment of noncomplex pleural disease. J Thorac Cardiovasc Surg. 2003;126: 1618-23.

19. Futagawa K, Suwa I, Okuda T, Kamamoto H, Sugiura J, Kajikawa, et al. Anesthetic management for the minimally invasive Nuss procedure in 21 patients with pectus excavatum. J Anesth. 2006;20:48-50.
20. Croitoru DP, Kelly RE, Goretsky MJ, Gustin T, Keever R, Nuss D. The minimally invasive Nuss technique for recurrent or failed pectus excavatum repair in 50 patients. J Pediatr Surg. 2005;40: 181-7.

21. Wong DH, Ward MG. A preventable cause of brachial plexus injury. Anesthesiology. 2003;98:798.

22. Cheney FW, Domino KB, Caplan RA, Posner KL. Nerve injury associated with anesthesia: a closed claims analysis. Anesthesiology. 1999;90:1062-9. 